\title{
EXTRAÇÃO, PRECIPITAÇÃO E RETICULAÇÃ̃O DA MUCILAGEM DE JARACATIÁ (CARICA QUERCIFOLIA (A. ST.-HIL) HIERON) PARA USO COMO ADSORVENTE DE PROTEÍNAS
}

\author{
H. M. HEIDEMANN ${ }^{1}$, C. FACCIO ${ }^{1}$, M. G. N. QUADRI ${ }^{1}$, R. C. $\operatorname{ALVES}^{1}$ e S. R. ZOLDAN ${ }^{2}$ \\ ${ }^{1}$ Universidade Federal de Santa Catarina, Departamento de Engenharia Química e Engenharia \\ de Alimentos \\ ${ }^{2}$ Empresa de Pesquisa Agropecuária e Extensão Rural de Santa Catarina - EPAGRI, Campos \\ Novos/SC \\ E-mail para contato: mara@enq.ufsc.br
}

\begin{abstract}
RESUMO - A mucilagem é composta quimicamente por água, pectinas, açúcares e ácidos orgânicos, tornando-se viscosa na presença de água. O objetivo deste estudo foi a reticulação da mucilagem de jaracatiá (Carica quercifolia (A. St.-Hil.) Hieron) precipitada, a qual é composta por polissacarídeos naturais, para uso como adsorvente de proteínas, aproveitando assim os produtos da biodiversidade brasileira. Após a extração e precipitação com etanol, a mucilagem foi reticulada com epicloridrina. O rendimento da mucilagem de jaracatiá precipitada e da reticulação, os grupos funcionais antes e após a reticulação e a capacidade de adsorção do reticulado utilizando papaína foram avaliados. O rendimento da mucilagem precipitada em relação a massa de polpa do fruto foi de 1-1,5\% e, após a reticulação o rendimento ficou em torno de $20 \%$ de mucilagem reticulada em relação à massa inicial de mucilagem precipitada. Os espectros FTIR mostraram que houveram mudanças nas bandas características com a reticulação. A capacidade da adsorção de papaína mostrou-se satisfatória, em torno de $50 \%$.
\end{abstract}

\section{INTRODUÇÃO}

A cromatografia de afinidade é uma técnica tradicional para purificação de proteínas. A utilização de suportes do tipo membrana, utilizando polímeros sintéticos ou naturais, tais como celulose, quitosana, poliamida, poli (álcool vinílico), poli (metacrilato de hidroxietila) e polisulfona têm sido investigadas (Gebauer et al., 1996; Gan et al., 2000; Guo; Ruckenstein, 2001; Garipcan et al., 2001; Zou et al., 2001; Vyas et al., 2001; Srivastava et al., 2012; Lv et al., 2013).

Os polímeros sintéticos, apesar da alta produção, têm algumas desvantagens tais como elevado custo, toxicidade, promovem a poluição ambiental durante a síntese e geralmente são obtidos de fonte não renovável (Jani et al., 2009; Deogade et al., 2012). Já as gomas e mucilagens são naturais, biodegradáveis, biocompatíveis, atóxicas e apresentam boa relação custo-benefício (Bhardwaj et al., 2000; Yeole et al., 2006; Deogade et al., 2012).

Algumas plantas possuem a mucilagem como uma fração da composição polissacarídica que, in vivo atua como um reservatório de água, pois é um produto do metabolismo interno das 
células vegetais (Qadry, 2008), e após extração e processamento é capaz de se tornar viscosa na presença de água (Cárdenas et al., 1998). Fisicamente é um sistema coloidal líquido, liofílico, sendo, portanto, um hidrogel; quimicamente é constituída por água, pectinas, açúcares e ácidos orgânicos (Misaki et al., 1972). É uma substância translúcida, amorfa e heteropolimérica, formada por monossacarídeos ou mistura de monossacarídeos. Muitas mucilagens possuem a cadeia monossacarídica combinada com ácidos urônicos (Jani et al., 2009).

A reticulação consiste na formação de uma rede, onde as várias cadeias de um polissacárido são ligadas por ligações covalentes, tornando essas cadeias mais rígidas (Ganji; Vasheghami-Farahani, 2009) e em geral são promovidas por agentes de reticulação, os quais são substâncias que apresentam baixa massa molar e grupos funcionais reativos capazes de permitir a formação de ligações inter ou intracadeias poliméricas (Berger et al., 2004). Na reticulação química um número pequeno de ligações cruzadas entre as cadeias é suficiente para impedir sua separação e passagem para a solução, tornando assim o polímero insolúvel; observa-se que apenas uma ligação entre duas cadeias já é suficiente para que isso ocorra (Lucas et al., 2001)

Sendo a cromatografia uma das técnicas mais utilizadas para purificação de proteínas, há perspectivas para o desenvolvimento de suportes cromatográficos com o surgimento de novos materiais adsorventes. O objetivo do presente estudo foi avaliar a reticulação da mucilagem de jaracatiá precipitada e sua capacidade de atuar como adsorvente de proteínas.

\section{MATERIAIS E MÉTODOS}

\subsection{Materiais}

Os jaracatiás (Carica quercifolia (A. St.-Hil.) Hieron) foram obtidos através da EPAGRI - Campos Novos/SC e enviados ao LASIPO/ENQ/UFSC, os quais permaneceram congelados até o momento da extração. Uma exsicata da espécie (Carica quercifolia (A. St.-Hil.) Hieron) foi depositada no Herbário do Instituto de Biociências (Herbário ICN) da Universidade Federal do Rio Grande do Sul sob o número de tombo ICN 173708. Todos os experimentos foram realizados em duplicata.

\subsection{Métodos}

Extração e precipitação: A mucilagem (proporção polpa/água de 1:1,25) foi extraída manualmente do jaracatiá descascado e triturado brevemente em liquidificador. A suspensão foi filtrada em malha de poliéster com auxílio de vácuo e precipitada com etanol 92,8 $8^{\circ}(1: 3)$. O precipitado foi seco em estufa $40{ }^{\circ} \mathrm{C}$ por 48 horas.

Reticulação: A reticulação seguiu a metodologia de Teixeira-Sá et al. (2009), onde usouse $1 \mathrm{~g}$ de mucilagem precipitada, $0,3 \mathrm{~mL}$ de epicloridrina e $3 \mathrm{~mL}$ de solução de hidróxido de sódio $3 \mathrm{M}$. A mistura foi deixada em estufa por 24 horas a $40^{\circ} \mathrm{C}$, e por 12 horas a $70{ }^{\circ} \mathrm{C}$. $\mathrm{O}$ reticulado foi lavado com água destilada até atingir $\mathrm{pH}$ neutro e armazenado em solução de $\mathrm{NaCl}$ 0,15 N, ácido ascórbico e azida sódica, sob refrigeração até o momento do uso. 
Rendimento: Os jaracatiás (Carica quercifolia (A. St.-Hil.) Hieron) foram descascados e avaliado o percentual de casca e polpa. O rendimento da mucilagem precipitada em relação à polpa, foi avaliado a partir da massa de mucilagem precipitada obtida após a extração, precipitação e secagem. Para o rendimento da reticulação, foi avaliada a massa de mucilagem precipitada reticulada em relação à massa inicial de mucilagem utilizada após a reticulação e secagem.

Espectroscopia no infravermelho com transformada de Fourier (FTIR): As amostras foram analisadas por espectroscopia na região do infravermelho com transformada de Fourier (FTIR), em um espectrofotômetro FTIR Shimadzu modelo IRP Prestige-21 com detector DLATGS, com faixa espectral de $400 \mathrm{~cm}^{-1}$ a $4000 \mathrm{~cm}^{-1}$ e resolução de $2 \mathrm{~cm}^{-1}$, por transmissão em pastilhas de $\mathrm{KBr}$ de 7 mm de diâmetro (200-300 mg).

Ponto de carga zero: A metodologia proposta por Ferro-García et al. (1998), com algumas modificações, foi utilizada na determinação do ponto de carga zero, $\mathrm{pH}_{\mathrm{pcz}}$, onde $50 \mathrm{~mL}$ de solução de $\mathrm{NaCl}$ 0,01 mol.L ${ }^{-1}$, foram adicionados em frascos erlemneyers, e quantidades préestabelecidas de solução de $\mathrm{HCl} 0,1 \mathrm{M}$ ou $\mathrm{NaOH} 0,1 \mathrm{M}$ foram adicionados para se obter valores de $\mathrm{pH}$ entre 1 e 12. Em seguida $0,10 \mathrm{~g}$ de mucilagem precipitada reticulada foi adicionada em cada frasco e os mesmos agitados em shaker a temperatura ambiente, por 24 horas. Após esse período, o pH de equilíbrio foi medido.

Capacidade de adsorção: Foi preparada uma solução de papaína $0,5 \%$, a qual foi deixada em contato com a mucilagem de jaracatiá (Carica quercifolia (A. St.-Hil.) Hieron) precipitada e reticulada com epicloridrina (1,5 g em $50 \mathrm{~mL}$ de solução) em tempos pré-estabelecidos sob agitação leve e temperatura ambiente. $\mathrm{O}$ processo foi acompanhado ao longo do tempo para obtenção da cinética de adsorção; as medidas de variação do teor proteico foram feitas em espectrofotômetro no comprimento de onda 290 ఛm. A concentração foi calculada de acordo com uma curva padrão de papaína.

\section{RESULTADOS E DISCUSSÃO}

\subsection{Rendimento}

Para os experimentos foram utilizadas $300 \mathrm{~g}$ de jaracatiás (Carica quercifolia (A. St.Hil.) Hieron). Depois de descascados, a massa total de polpa/sementes foi de $200 \mathrm{~g}$, apresentando, assim, um rendimento de $66,67 \%$ de polpa/semente e $33,33 \%$ de casca. $\mathrm{Na}$ precipitação o rendimento ficou em torno de $1-1,5 \%$. O rendimento da mucilagem reticulada em relação à massa inicial de mucilagem precipitada foi de $25 \%$.

\subsection{Espectroscopia no infravermelho com transformada de Fourier (FTIR)}

Os espectros na região do infravermelho obtidos das mucilagens de jaracatiá precipitada e reticulada com epicloridrina são mostrados na Figura 1. 


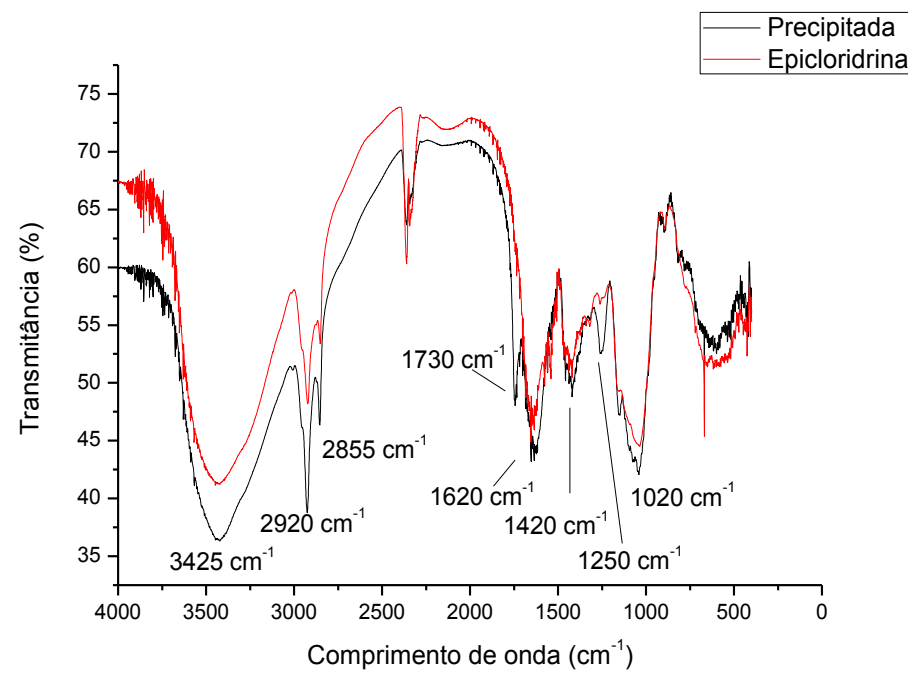

Figura 1 - Espectro de FTIR da mucilagem de jaracatiá precipitada e reticulada com epicloridrina.

Ambas as mucilagens, reticulada e não reticulada, apresentaram uma banda forte e larga em $3425 \mathrm{~cm}^{-1}$, que pode ser atribuída ao estiramento vibracional do grupo O-H de água e álcoois (Silverstein et al., 2006; Pavia et al., 2008; Yuen et al., 2009). Houve uma redução na intensidade das bandas $2920 \mathrm{~cm}^{-1}$ e $2855 \mathrm{~cm}^{-1}$, as quais são atribuídas às vibrações simétricas e assimétricas do grupamento C-H (Silverstein et al., 2006; Tavares et al., 2011) quando a amostra foi reticulada. A banda característica de grupos carbonila $(\mathrm{C}=\mathrm{O})$ de éster, em $1730 \mathrm{~cm}^{-}$ 1, e a banda de estiramento do grupo C-O, em $1250 \mathrm{~cm}^{-1}$ desapareceram, enquanto que a banda em $1620 \mathrm{~cm}^{-1}$ teve uma leve diminuição na intensidade, sendo esta atribuída ao grupo $\mathrm{C}=\mathrm{O}$ de ácido (Pavia et al., 2008; Tavares et al., 2011). A banda em $1020 \mathrm{~cm}^{-1}$ também teve uma leve diminuição na intensidade, e está relacionada à deformações simétricas e assimétricas do grupo C-OH (Tavares et al., 2011). De acordo com Gonsalves e Araújo (2011), a epicloridrina é considerada um reticulante ligante de $-\mathrm{OH}$.

\subsection{Ponto de carga zero $\left(\mathrm{pH}_{\mathrm{pcz}}\right)$}

A Figura 2 mostra os pontos experimentais utilizados na obtenção do $\mathrm{pH}_{\mathrm{pcz}}$ da mucilagem de jaracatiá precipitada e reticulada com epicloridrina. 


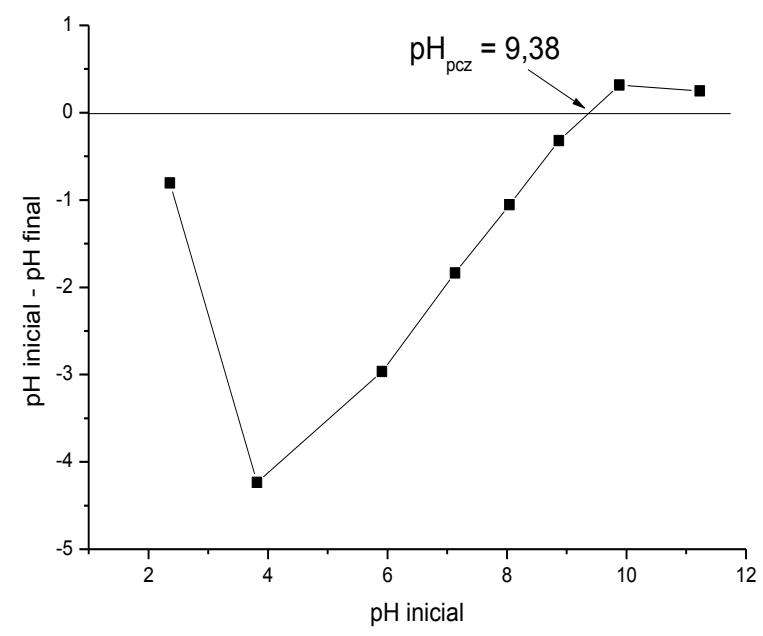

Figura 2 - Resultados experimentais obtidos na determinação do $\mathrm{pH}_{\mathrm{pcz}}$ da mucilagem de jaracatiá precipitada e reticulada com epicloridrina.

O ponto de carga zero $\left(\mathrm{pH}_{\mathrm{pcz}}\right)$ é o $\mathrm{pH}$ no qual a superfície é neutra (Guilarduci et al., 2006). Na solução de mucilagem de jaracatiá (Carica quercifolia (A. St.-Hil.) Hieron) precipitada e reticulada com epicloridrina, em $\mathrm{pH}$ abaixo de 9,38 a superfície atrairá preferencialmente ânions por estar protonada e carregada positivamente. De maneira oposta, acima de $\mathrm{pH}$ 9,38, a superfície da mucilagem encontra-se desprotonada e negativamente carregada, exercendo atração preferencial sobre cátions.

\subsection{Capacidade de adsorção}

Os dados obtidos da adsorção estão na Tabela 1.

Tabela 1 - Dados obtidos na adsorção da solução de papaína.

\begin{tabular}{|c|c|c|}
\hline \multirow{2}{*}{$\begin{array}{c}\text { Tempo } \\
(\min )\end{array}$} & \multicolumn{2}{|c|}{ Reticulada com epicloridrina } \\
\hline & $\begin{array}{l}\text { Concentração } \\
\left(\mathrm{mg}^{-\mathrm{g}^{-1}}\right)\end{array}$ & $\begin{array}{c}\text { Adsorção } \\
(\%)\end{array}$ \\
\hline 0 & 1,66 & 0 \\
\hline 15 & 1,03 & 37,95 \\
\hline 30 & 0,93 & 43,97 \\
\hline 45 & 0,81 & 51,20 \\
\hline 60 & 0,80 & 51,81 \\
\hline
\end{tabular}

Os testes de adsorção mostraram que a mucilagem de jaracatiá (Carica quercifolia (A. St.-Hil.) Hieron) precipitada e reticulada com epicloridrina pode ser utilizada na purificação de proteínas, pois como pode ser observado na Tabela 1, em 60 minutos em torno de $50 \%$ da papaína foi adsorvida. A capacidade da adsorção de papaína mostrou-se satisfatória, pois mesmo com tempo de contato baixo e uso de uma quantidade pequena de adsorvente, teve-se 
uma quantidade razoável de papaína adsorvida, mostrando assim a boa afinidade entre o adsorvente e o adsorbato.

Benhura e Mavhudzi (1996), utilizaram a mucilagem de ruredzo (Dicerocaryum zanguebarium) reticulada com epicloridrina para purificar a poligalacturonase extraída do tomate. Como podemos verificar houve ótima afinidade entre a mucilagem reticulada e a proteína, pois obtiveram um rendimento na purificação de $100 \%\left(5,2 \mathrm{mg} \cdot \mathrm{g}^{-1}\right)$.

Teixeira-Sá et al. (2009), purificaram a lectina por cromatografia de afinidade, onde reticularam com epicloridrina os polissacarídeos extraídos de Mucuna sloanei e utilizaram como adsorvente, com isso obtiveram um rendimento na purificação da lectina de $5.4 \mathrm{mg} . \mathrm{g}^{-1}$.

\section{CONCLUSÃO}

Nas condições experimentais em que foi realizado o presente trabalho, os resultados obtidos permitiram concluir que:

- $\quad$ Os grupos funcionais encontrados na mucilagem de jaracatiá (Carica quercifolia (A. St.Hil.) Hieron) precipitada e reticulada mostraram mudanças na intensidade e/ou o não aparecimento de algumas bandas características, quando comparadas.

- $\quad$ O estudo do ponto de carga zero das soluções de mucilagens de jaracatiá (Carica quercifolia (A. St.-Hil.) Hieron) precipitada e reticulada com epicloridrina obteve $\mathrm{pH}_{\mathrm{pcz}}$ de 9,38 .

- $\quad$ Os testes de adsorção mostraram que a mucilagem reticulada com epicloridrina pode ser utilizada na purificação de proteínas (em 60 minutos em torno de $50 \%$ da solução de papaína foi adsorvida).

- $\quad$ O rendimento médio da mucilagem de jaracatiá (Carica quercifolia (A. St.-Hil.) Hieron) precipitada e reticulada em relação à massa inicial de mucilagem precipitada foi de $25 \%$.

\section{AGRADECIMENTOS}

Empresa de Pesquisa Agropecuária e Extensão Rural de Santa Catarina - EPAGRI, Campos Novos/SC.

Laboratório de Controle de Processos do Departamento de Engenharia Química da Universidade Federal de Santa Catarina.

\section{REFERÊNCIAS}

BENHURA, M. A. N.; MAVHUDZI, I. Use of crosslinked mucilage prepared from ruredzo (Dicerocaryum zanguebarium) in the purification of polygalacturonase extracted from tomato. Food Chem., v. 56, p. 433-437, 1996.

BERGER, J.; REIST, M.; MAYER, J. M.; FELT, O.; PEPPAS, N. A.; GURNY, R. Structure and interactions in covalently and ionically crosslinked chitosan hydrogels for biomedical applications. Eur. J. Pharm. Biopharm., v. 57, p. 19-34, 2004.

BHARDWAJ, T. R.; KANWAR, M.; LAL, R.; GUPTA, A. Natural gums and modified natural gums as sustained-release carriers. Drug Dev. Ind. Pharm., v. 26, p. 1025-1038, 2000. 
CÁRDENAS, A.; ARGUELLES, W. M.; GOYCOOLEA, F. On the posible rol of Opuntia ficus-indica Mucilage in Lime Mortar Perfomance in the Protection of Historical Buildings. $J$. Profess. Assoc. Cactus Developm., v. 3, 1998.

DEOGADE, U. M.; DESHMUKH, V. N.; SAKARKAR, D. M. Natural Gums and Mucilage's in NDDS: Applications and Recent approaches. Int. J. PharmTech Res., v.4, p 799-814, 2012.

FERRO-GARCÍA, M. A.; RIVERA-UTRILLA, J.; BAUTISTA-TOLEDO, I.; MORENOCASTILLA, C. Adsorption of humic substances on activated carbon from aqueous solutions and their effect on the removal of Cr (III) ions. Langmuir, v. 14, p. 1880-1886, 1998.

GAN, H. Y.; SHANG, Z. H.; WANG, J. D. New affinity nylon membrane used for adsorption of g-globulin. J. Chromatogr.A, v. 867, p. 161-168, 2000.

GANJI, F.; VASHEGHAMI-FARAHANI, E. Hydrogels in controlled drug delivery systems. Iran. Polym. J., v. 18, p. 63-88, 2009.

GARIPCAN, B.; BERELI, N.; PATIR, S.; ARICA, M. Y.; DENIZLI, A. Synthesis of poly[(hydroxyethyl methacrylate)-co-(methacrylamidoalanine)] membranes and their utilization as an affinity sorbent for lysozyme adsorption. Macromol. Biosci., v. 1, p. 332-340, 2001.

GEBAUER, K. H.; THÖMMES, J.; KULA, M. R. Breakthrough performance of high-capacity membrane adsorbers in protein chromatography. Chem. Eng. Sci., v. 52, p. 405-419, 1996.

GONSALVES, A. DE A.; ARAÚJO, C. R. M. Diferentes estratégias para a reticulação de quitosana. Quim. Nova, v. 34, p. 1215-1223, 2011.

GUIlARDUCI, V. V. S.; MESQUitA, J. P.; MARTElli, P. B.; GORGUlhO, H. F. Adsorção de fenol sobre carvão ativado em meio alcalino. Quím. Nova, v. 29, p. 1226-1232, 2006.

GUO, W.; RUCKENSTEIN, E. A new matrix for membrane affinity chromatography and its application to the purification of concanavalin A. J. Membr. Sci., v. 182, p. 227-234, 2001.

JANI, G. K.; SHAH, D. P.; PRAJAPATI, V. D.; JAIN, V. C. Gums and mucilages: versatile excipients for pharmaceutical formula-tions. Asian J Pharm Sci., v. 4, p. 309-323, 2009.

LUCAS, E. F.; SOARES, B. G.; MONTEIRO, E. Caracterização de Polímeros Determinação de Peso Molecular e Análise Térmica. Série Instituto de Macromoléculas. Ed. e-papers, Rio de Janeiro, 2001, 366 p.

LV, Y.; BAO, X.; LIU, H.; REN, J.; GUO, S. Purification and characterization of cacliumbinding soybean protein hydrolysates by $\mathrm{Ca}^{2+} / \mathrm{Fe}^{3+}$ immobilized metal affinity chromatography (IMAC). Food Chem., v. 141, p. 1645-1650, 2013.

MISAKI, A.; ITO, T.; HARADA, T. Constitutional Studies on the Mucilage of "Yamanoimo" Dioscorea batatas Decne, forma Tsukune: isolation and structure of a mannan. Agric. Biol. Chem., v. 36, p. 761-771, 1972.

PAVIA, D. L.; KRIZ, G. S.; LAMPMAN, G. M. Introduction to Spectroscopy. Fourth Edition. Brooks Cole, 2008.

QADRY, J. S. Shah and Qadry's Pharmacognosy. Ahmedabad, Índia: B S Shah Prakashan, 2008. 
RODRIGUES, J. F.; PAULA, R. C. M.; COSTA, S. M. O. Métodos de Isolamento de Gomas Naturais: Comparação através da goma do Cajueiro (Anacardium occidentale L). Polímeros, Jan/Mar, p. 31-36, 1993.

SILVERSTEIN, R. M.; WEBSTER, F. X.; KIEMLE, D. J. Identificação espectrofotométrica de compostos orgânicos. $7^{\mathrm{a}}$ edição, Rio de Janeiro: LTC, 2006.

SRIVASTAVA, P.; RAUT, H. N.; WAGH, R. S.; PUNTAMBEKAR, H. M.; KULKARNI, M. J. Purification and characterization of an antioxidant protein $(\sim 16 \mathrm{kDa})$ from Terminalia chebula fruit. Food Chem., v. 131, p. 141-148, 2012.

TAVARES, S. A.; PEREIRA, J.; GUERREIRO, M. C.; PIMENTA, C. J.; PEREIRA, L.; MISSAGIA, S. V. Physical and chemical characteristics of the mucilage of lyophilized yam. Ciênc. Agrotec., v. 35, p. 973 -979, 2011.

TEIXEIRA-SÁ, D. M. A.; REICHER, F.; BRAGA, R. C.; BELTRAMINI, L. M. Isolation of a lectin and a galactoxyloglucan from Mucuna sloanei seeds. Phytochem., v. 70, p. 1965-1972, 2009.

VYAS, P. V.; SHAH, B. G.; TRIVEDI, G. S.; RAY, P.; ADHIKARY, S. K.; RANGARAJAN, R. Characterization of heterogeneous anion-exchange membrane. J. Membr. Sci., v. 187, p. 3946, 2001.

YEOLE, P. G.; NAKHAT, P. D.; GALGATTE, U. C.; BABLA, I. C. Design and evaluation of xanthan gum-based sustained release matrix tablets of diclofenac sod. Indian J. Pharm. Sci., v. 68, p. 185-189, 2006.

YUEN, S.-N.; CHOI, S.-M.; PHILLIPS, D. L.; MA, C.-Y. Raman and FTIR spectroscopy study of carboxymethylated non-starch polysaccharides. Food Chem., v. 114, p. 1091-1098, 2009.

ZOU, H. F.; LUO, Q. Z.; ZHOU, D. M. Affinity membrane chromatography for the analysis and purification of proteins. J. Biochem. Bioph. Methods, v. 49, p. 199-240, 2001. 